\title{
Anomalías y displasias dentarias de origen genético-hereditario
}

\section{Inherited dental abnormalities and dysplasias}

\author{
Martín-González J*, Sánchez-Domínguez B*, Tarilonte-Delgado ML*, \\ Castellanos-Cosano L*, Llamas-Carreras JM*, López-Frías FJ*, Segura-Egea JJ*
}

\section{RESUMEN}

Las alteraciones del desarrollo embriológico de la dentición provocan anomalías y displasias dentarias. Los factores etiopatogénicos implicados en las alteraciones del desarrollo dentario son básicamente dos: genéticos y ambientales. Según la fase del desarrollo en que afecten al órgano del esmalte y a los tejidos dentarios, aparecerán diferentes anomalías y/o displasias dentales. El control genético del desarrollo dentario se lleva a cabo mediante dos procesos: a) control de la histogénesis del esmalte y la dentina, y b) la especificación del tipo, tamaño y posición de cada diente. La mutación de los genes implicados en la amelogénesis (AMELX, ENAM, MMP20 y KLK4) o en la dentinogénesis (DSPP) produce alteraciones del desarrollo dentario aisladas o no sindrómicas. Por el contrario, las mutaciones de los genes reguladores morfogenéticos involucrados en la determinación de la posición y el desarrollo precoz de los órganos dentarios (genes homeobox), además de alterar la morfodiferenciación dentaria, tienen efectos pleiotrópicos y afectan a otros órganos, provocando síndromes hereditarios en los que uno de sus rasgos es la alteración dentaria. En este artículo se revisan las principales anomalías y displasias dentarias de causa genético-hereditaria.

Palabras clave: Anomalía dentaria, displasia dentaria, amelogénesis, dentinogénesis, genes homeobox, enfermedades raras, agenesias dentarias.

\section{SUMMARY}

Alterations of the embryologic development of the dentition cause dental anomalies and dysplasias. The causing factors involved in the disturbances of tooth development are basicallytwo: genetic and environmental factors. Depending on the phase of tooth development when the factors act, they will appear different dental anomalies and dysplasias. Genetic control of tooth development is carried out through two processes: a) control of amelogenesis and dentinogenesis, and b) the specification of the type, size and position of each tooth. Mutation of genes involved in amelogenesis (AMELX, ENAM, MMP20 and KLK4) and dentinogenesis (DSPP) produces non-syndromicalterations of tooth development. On the contrary, mutations in morphogenetic regulatory genes involved in determining the position and the early development of the teeth (homeobox genes), not only alter teeth morphodifferentiation, but also have pleiotropic effects affecting other organs, causing hereditary syndromes in which one of its features is the presence of dental abnormalities. Dental anomalies and dysplasias of genetic origin are reviewed in this article.

Key words: Dental anomalies, dental dysplasia, amelogenesis, dentinogenesis, rare disease, homeobox gene.

Fecha de recepción: 10 de enero de 2012.

Aceptado para publicación: 22 de febrero de 2012.

Martín-González J, Sánchez-Domínguez B, Tarilonte-Delgado ML, Castellanos-Cosano L, Llamas-Carreras JM, López-Frías FJ, Segura-Egea JJ. Anomalías y displasias dentarias de origen genético-hereditario. Av. Odontoestomatol 2012; 28 (6): 287-301. 


\section{INTRODUCCIÓN}

La odontogénesis se inicia en la $6^{\mathrm{a}}$ semana de vida intrauterina, cuando se diferencia la lámina dental a partir del epitelio odontógeno. En la $8^{\mathrm{a}}$ semana aparecen los diez brotes o yemas correspondientes a los dientes primarios, cada uno de los cuales origina un órgano del esmalte. Cada brote permanece conectado al epitelio odontógeno a través de un pedículo, el gubernaculumdentis, una expansión del cual originará la lámina accesoria de la que se formarán los gérmenes de los dientes permanentes. Una extensión distal de la lámina dental originará los gérmenes de los molares permanentes.

Las alteraciones del desarrollo embriológico de la dentición se denominan anomalías dentarias, utilizándose también el término displasias dentarias para los casos en los que se altera el desarrollo de un tejido dentario específico.

Anómalo significa desigual, diferente, distinto, que discrepa de la regla. Por tanto, la anomalía dentaria puede definirse como una desviación de la normalidad dentaria provocada por una alteración en el desarrollo embriológico del diente. La anomalía puede afectar a cualquiera de los aspectos de la normalidad dentaria: la forma, el número, el tamaño, la estructura interna, el color, la posición en la arcada, etc. No obstante, el establecer un límite entre lo normal y lo patológico en ocasiones es complicado. Si comparamos individuos y razas, el tamaño y la forma pueden variar bastante. Lo que en una etnia es habitual, en otra es un hallazgo extraordinario y anómalo. Así, la raíz distobucal en el primer molar inferior, los rebordes marginales hipertróficos y el cíngulo hiperplásico en los incisivos superiores es frecuente en el patrón dental sinodonte o mongoloide, propio de las razas de origen mongoloide (asiáticos septentrionales, japoneses, chinos, mongoles, siberianos y amerindios), pero es una anomalía en el patrón dental occidental propio de la raza caucásica (euroasiáticos y africanos). El concepto "normalidad dentaria" es, pues, relativo, existiendo cuando la persona tiene el número y tipo de dientes común para su edad, situados en las arcadas en el orden y posición habitual, con la forma característica de cada pieza, el tamaño adecuado, el color ordinario y la estructura interna específica, dentro del contexto racial al que pertenece.

\section{ORIGEN GENÉTICO DE LAS ANOMALÍAS DENTARIAS}

Los factores que provocan anomalías dentarias actúan a partir del segundo mes de vida intrauterina y, según la fase del desarrollo en que se encuentre el órgano del esmalte y los tejidos dentarios que se afecten, aparecerán anomalías dentarias del número (1) posición $(2,3)$ forma (4), tamaño (5), color o estructura interna $(6,7)$, o bien displasias de algún tejido dentario.

Los factores etiopatogénicos implicados en las alteraciones del desarrollo dentario son básicamente dos: 1) genético-hereditarios y 2) ambientales. Aunque en este caso nos vamos a centrar en los factores genético-hereditarios, el normal desarrollo del germen dentario puede verse también afectado por factores ambientales sistémicos (tetraciclinas, flúor) o locales (presión externa, proceso inflamatorio cercano, traumatismos, alteraciones localizadas del trofismo nervioso, circulatorio o endocrinometabólico), apareciendo displasias de esmalte o dentina y anomalías dentarias cuya expresión fenotípica dependerá de la fase del desarrollo dentario en la que hayan actuado estos factores.

Por lo que al factor genético se refiere, la mutación de alguno de los genes implicados en la amelogénesis o la dentinogénesis, puede provocar displasias y anomalías dentarias. El control genético del desarrollo dentario se lleva a cabo mediante dos procesos: a) el control de la histogénesis del esmalte y la dentina y b) la especificación del tipo, tamaño y posición de cada diente.

Los genes implicados en la amelogénesis (AMELX, ENAM, MMP20 y KLK4) y en la dentinogénesis (DSPP) son altamente específicos para los dientes, por lo que sus mutaciones producen alteraciones del desarrollo dentario no sindrómicas. La alteración es dentaria, sin que haya anomalías en otros órganos. Es el caso de las displasias de los tejidos dentarios (amelogénesis imperfecta, dentinogénesis imperfecta y displasias dentinarias) y de las anomalías en el número dentario (hipo, oligo o anodoncia) que se presentan de forma aislada, sin asociarse a síndrome hereditario alguno.

Por el contrario, varios genes con funciones reguladores morfogenéticas involucrados en la determina- 
ción de la posición y el desarrollo precoz de los órganos dentarios, están también implicados en la morfogénesis de otros órganos (8) La mutación de estos genes, además de alterar la morfodiferenciación dentaria, puede tener efectos pleiotrópicos y afectar a otros órganos, provocando síndromes hereditarios en los que uno de sus rasgos es la presencia de anomalías dentarias. Así, los genes homeobox (HOX genes) controlan el desarrollo del germen dentario durante las semanas 18-24, especialmente en lo que se refiere a la posición, número y forma dentaria (9). Antes del desarrollo facial, existen áreas concretas, denominadas dominios, en las que se expresan determinados genes homeobox, determinando así el tipo de diente que puede desarrollarse en dicha área. Por ejemplo, los genes homeobox MSX1 MSX2 están relacionados con la región de los incisivos, estando sus mutaciones implicadas en las agenesias dentarias de incisivos, la presencia de hendidura palatina y el desarrollo de cáncer colorrectal. Los genes DLX1, DLX2 y el BARX1, implicados en el desarrollo craneofacial, están relacionados con las regiones de los molares y, en concreto, con el desarrollo de dientes multirradiculares.

\section{CLASIFICACIÓN DE LAS ALTERACIONES GENÉTICO-HEREDITARIAS DEL DESARROLLO DENTARIO}

Las alteraciones genéticas de la estructura dentaria pueden clasificarse según el tejido afectado (esmalte o dentina), según su patrón de herencia (autosómica dominante, autosómica recesiva y ligada al sexo) y según aparezcan aisladas (no sindrómicas) o formando parte de síndromes de anomalías congénitas múltiples (anomalías dentarias sindrómicas).

En un gran número de síndromes hereditario las anomalías dentarias, más o menos severas, constituyen un dato clínico importante que, en ocasiones, puede ser esencial para la confirmación del diagnóstico. La base de datos Winter-Baraitser v 1.0.12 (anteriormente: London Dysmorphology Database LDDB) recoge 793 entidades con anomalías dentarias, entre las cuales 147 son anomalías de la forma dentaria, 219 son ligodoncias, 28 son alteraciones de la dentina y 128 son displasias del esmalte. El portal Orphanet proporciona abundante información sobre síndromes de origen genético con alteraciones dentarias (10).

\section{ALTERACIONES GENÉTICAS DE LA AMELOGÉNESIS}

El esmalte es un tejido de origen ectodérmico con bajo contenido proteico y altamente mineralizado. El ameloblasto es la célula encargada de la formación del esmalte, que comienza en la séptima semana de gestación y continúa hasta después del nacimiento. La amelogénesis es un proceso complejo que comienza con la secreción por el ameloblasto de una matriz proteica (fase secretora) constituida por amelogenina (80-90\%), ameloblastina (5-10\%), enamelina (3-5\%) y enamelisina (1\%), además de por pequeñas cantidades de otras proteínas con actividad proteasa (plasminógeno, prostatina, hepsina, y calicreína). La precipitación de cristales de hidroxiapatita (fase de mineralización o calcificación) conlleva la progresiva mineralización de la matriz mediante el crecimiento en longitud de dichos cristales. Por último, la fase de maduración comienza con la degradación de la matriz proteica que rodea a los cristales, que es sustituida por materia mineral, con el consiguiente incremento en espesor de los cristales de hidroxiapatita, que contactan íntimamente con los cristales adyacentes.

\section{Amelogénesis imperfecta no sindrómica}

Las mutaciones en los genes que controlan la formación del esmalte y codifican la expresión de sus proteínas, producen alteraciones de los dientes sin afectar a otros órganos de la economía.

La amelogénesis imperfecta (AI) no sindrómicas un grupo clínica y genéticamente heterogéneo de alteraciones primarias del desarrollo histológico del esmalte. La prevalencia de AI varía en diferentes poblaciones, con un rango entre $1 / 700$ y $1 / 4.000$ personas. El tipo de herencia también es variable según las poblaciones. Un largo estudio epidemiológico desarrollado en 51 familias suecas (11) encontró un 6\% de casos con herencia recesiva ligada al sexo, un $63 \%$ de casos autosómico dominantes y un $12 \%$ de casos autosómico recesivos. El 19\% restante no te- 
nía un patrón claro de herencia o aparecía de forma esporádica. La AI tiene también gran variabilidad desde el punto de vista clínico, con manifestaciones que van desde la ausencia completa (aplasia) o parcial (hipoplasia) de formación del esmalte, hasta defectos en su mineralización (hipomineralización) y en su contenido proteico (hipomaduración) $(12,13)$, con cambios en el aspecto normal del esmalte que muestra descoloraciones mas o menos graves y opacidades blancas, amarillo-anaranjadas o marrones.

La clasificación más utilizada de la AI es la modificación realizada por Nusier en 2004 (13) de la propuesta por Witkop en 1988 (12), basada en el fenotipo y el tipo de herencia (Tabla 1). La utilización clínica de esta clasificación plantea el problema de la variabilidad de la expresión de la enfermedad en una misma familia y la falta de correlación entre el tipo de Al y el defecto molecular.

En la tabla 1 se muestran las características clínicas y radiográficas de las alteraciones del esmalte en cada uno de los tipos de AI. Basándose en la apariencia del esmalte y en el supuesto defecto del desarrollo que la ha originado, la AI no sindrómica puede clasificarse de forma sencilla en forma hipoplásica (defecto en la secreción de la matriz del esmalte por el ameloblasto) (Fig. 1), forma hipocalcificada (defecto en la mineralización de la matriz del esmalte) y forma de hipomaduración (defecto en el procesamiento de las proteínas y en la maduración de los cristales de hidroxiapatita) (14). Aunque estemos considerando a la AI como una patología no sindrómica, a los defectos del esmalte pueden asociarse muchas otras anomalías dentarias, como calcificaciones pulpares, taurodontismo, retraso en la erupción, hiperplasia gingival, mordida abierta y prognatismo (15).

La forma de AI más frecuente, la de herencia autosómica dominante, es también la de mayor variabilidad en la expresividad intrafamiliar. El gen que se afecta con mayor frecuencia es el de la enamelina (ENAM) (4q21), asociándose sus mutaciones con las

\section{TABLA 1.- CARACTERÍSTICAS CLÍNICAS Y RADIOGRÁFICAS DE LA AMELOGENESIS IMPERFECTA APLICADAS A LA CLASIFICACIÓN DE WITKOP REVISADA POR NUSIER Y COLS. (EN ITÁLICA)}

\begin{tabular}{|ll|l|l|}
\hline Tipo AI & Aspecto clínico & Aspecto radiográfico \\
\hline Hipoplásica (tipo I) & $\begin{array}{l}\text { Hipoplásica, } \\
\text { generalizada } \\
\text { (Tipo IG) }\end{array}$ & $\begin{array}{l}\text { Esmalte delgado, rugoso, } \\
\text { irregular, bandas, puntos. } \\
\text { Dientes pequeños, con } \\
\text { diastemasinterdentarios. }\end{array}$ & $\begin{array}{l}\text { Hipoplasia del esmalte, } \\
\text { más en los } 2 / 3 \text { coronales. } \\
\text { Espesor reducido del } \\
\text { esmalte. }\end{array}$ \\
& $\begin{array}{l}\text { Hiploplásica, } \\
\text { localizada } \\
\text { (Tipos I A-F) }\end{array}$ & $\begin{array}{l}\text { Esmalte delgado, rugoso, } \\
\text { sólo en parte de la corona. }\end{array}$ & $\begin{array}{l}\text { Hipoplasia difícil de } \\
\text { apreciar. }\end{array}$ \\
\hline Hipomineralización & $\begin{array}{l}\text { Hipocalcificación } \\
\text { (Tipo III) }\end{array}$ & $\begin{array}{l}\text { Esmalte blando y quebradizo. } \\
\text { Sufre gran atrición y, al final, } \\
\text { sólo persiste a nivel cervical. } \\
\text { Dentina expuesta. } \\
\text { Color amarillo-anaranjado. }\end{array}$ & $\begin{array}{l}\text { Espesor preeruptivo del } \\
\text { esmalte normal. } \\
\text { Radiolucidez del esmalte } \\
\text { menor que la dentina. }\end{array}$ \\
& $\begin{array}{l}\text { Hipomaduración } \\
\text { (Tipo II) }\end{array}$ & $\begin{array}{l}\text { Aspecto calcáreo, blanco, } \\
\text { marrón, anaranjado. }\end{array}$ & $\begin{array}{l}\text { Esmalte de grosor normal } \\
\text { Igual de radiolúcido que }\end{array}$ \\
& la dentina.
\end{tabular}




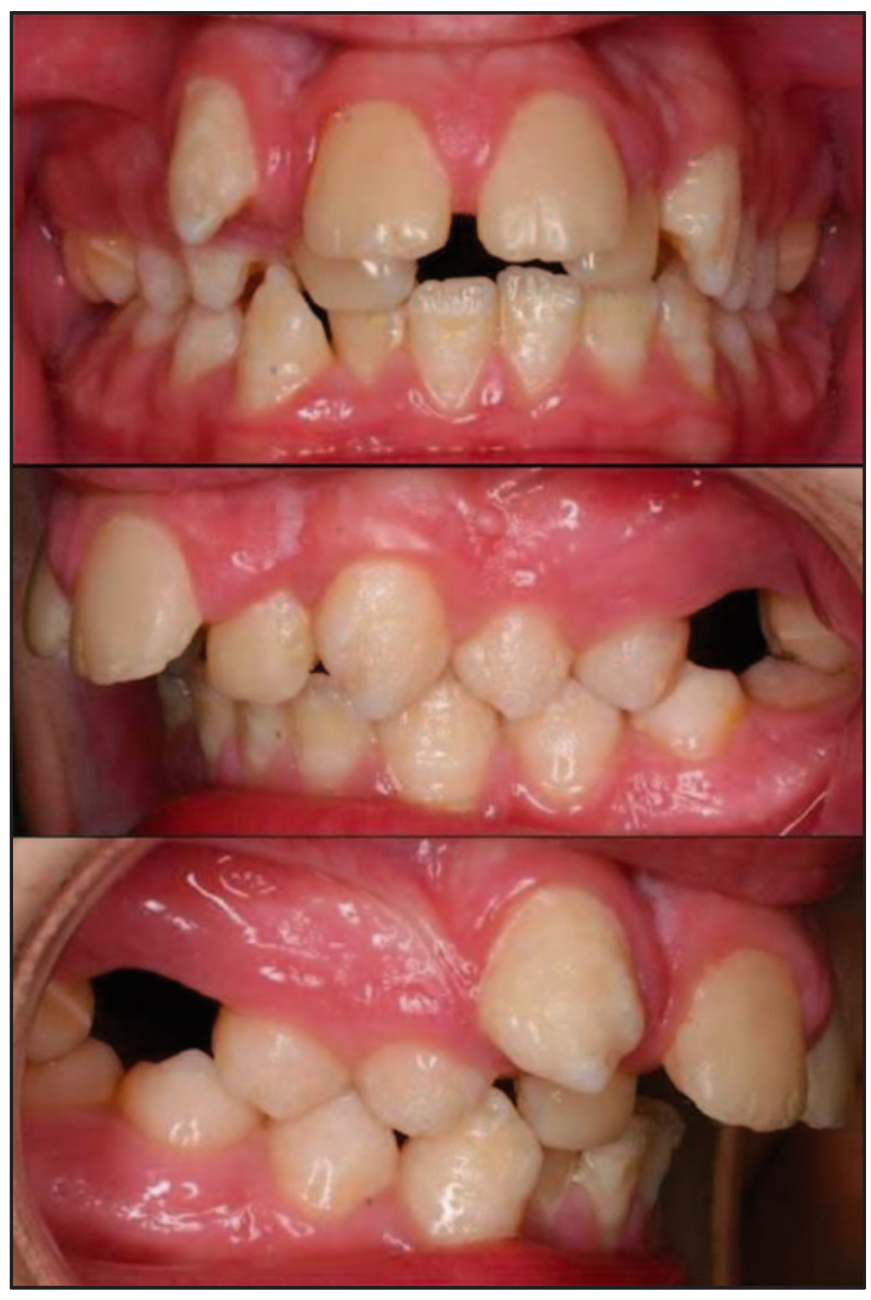

Fig. 1. Amelogénesis imperfecta tipo hipoplásico. Además de las lesiones hipoplásicas del esmalte, se observa un gran resalte.

formas hipoplásicas de AI de herencia dominante en las que es característico el esmalte picoteado. En la Al de herencia autosómica recesiva también se encuentran, en la mayoría de los casos, mutaciones del gen ENAM que se asocian en esta ocasión a mordida abierta, que sería un rasgo de herencia recesiva.

En las formas de AI ligadas al sexo, la mutación se produce en el gen de la amelogenina, localizado en los locus Xp22.1-p22.3 (AMELX) e Yp11.2 (AMELY). Los niveles de expresión de amelogenina para el gen AMELY son tan sólo del $10 \%$ comparado al gen AMELX, por lo que la mutación de este provoca un déficit de la proteína que fenotípicamente se manifiesta como alteraciones del color dentario que van del amarillo al marrón, con o sin opacidades. Los dientes pueden ser de tamaño normal o microdónticos, dependiendo del espesor de la capa de esmalte. La superficie puede ser lisa o rugosa. Las mujeres portadoras suelen presentar un patrón de esmalte con estrías verticales, resultado de la activación de ameloblastos normales y anormales.

El diagnóstico de $\mathrm{Al}$ involucra examen clínico, radiográfico, histológico y genético. Los dos primeros exámenes permiten realizar un diagnóstico presuntivo mientras que los dos últimos permiten un diagnóstico definitivo.

\section{Síndromes asociados con amelogénesis imperfecta e hipoplasias del esmalte}

Aunque la forma mas frecuente de AI es la no sindrómica o aislada, también puede presentarse asociada a otras alteraciones. La mutación de algunos genes conlleva la aparición no sólo de anomalías dentarias, sino también de alteraciones en diferentes órganos y sistemas. Comentamos a continuación los síndromes hereditarios en los que con mayor frecuencia se asocian alteraciones del desarrollo del esmalte.

Síndrome trico-dento-óseo: Pertenece al grupo de las displasias ectodérmicas y se caracteriza por cabellos crespos o rizados desde el nacimiento, hipoplasia del esmalte con descoloración y taurodontismo en molares, aumento de la densidad mineral ósea (DMO) general y aumento en el grosor de los huesos corticales del cráneo. La enfermedad se ha descrito en, al menos, 8 familias, con más de 30 miembros afectados relacionados por algún grado de parentesco. Las características más consistentes son hipoplasia del esmalte y taurodontismo; sin embargo, el grado de los defectos del esmalte también puede variar entre los miembros de la familia afectados. Las manifestaciones del pelo y los huesos son más variables y dependen de la edad. La enfermedad se transmite como un rasgo autosómico dominante altamente penetrante y está causada por mutaciones en el gen homeobox DLX3 (17q21.3-q22). El diagnóstico diferencial debe incluir la amelogénesis imperfecta de tipo hipomaduración hipoplásica con taurodontismo, la displasia oculo-dento-ósea, y la forma autosómica dominante 
de la osteopetrosis. El tratamiento es sintomático y los pacientes requieren un seguimiento dental frecuente.

Síndrome de Jalili: Se caracteriza por la asociación de AI y distrofia de conos y bastones, un raro trastorno de la retina que provoca inicialmente pérdida de la visión central, defectos en la visión de los colores y fotofobia antes de los 10 años de edad y, posteriormente, ceguera nocturna y disminución del campo de visión. El esmalte dental puede ser fino pero normal, o estar hipomineralizado. Se transmite de manera autosómica recesiva por una mutación en el gen CNNM4 (2q11.2).

Síndrome de Kohlschüttere-Tönz: El síndrome amelo-cerebro-hipohidrótico es un trastorno degenerativo caracterizado por amelogénesis imperfecta, convulsiones, regresión mental y dientes amarillos debido a defectos del esmalte. La espasticidad y el retraso en el desarrollo son también manifestaciones variables. Se transmite como un carácter autosómico recesivo.

Síndrome de McGibbon: Se asocian AI y nefrocalcinosis. El esmalte es muy delgado o está ausente (AI tipo hipoplásica), hay calcificaciones intrapulpares, retraso en la erupción, hipertrofia gingival, nefrocalcinosis bilateral y normalidad de la calcemia. La insuficiencia renal es variable y suele retrasarse hasta la edad adulta. En todos los pacientes con AI debe realizarse una ecografía renal para excluir la presencia de nefrocalcinosis asociada.

Raquitismo tipo II resistente a la vitamina D: Está producido por la mutación del gen que codifica el receptor de la vitamina $D(12 q 12-q 14)$ y se define por su resistencia al tratamiento con vitamina $\mathrm{D}$. La vitamina D controla las etapas del desarrollo de la corona dentaria así como a varios de los genes implicados en la amelogénesis imperfecta. Los signos típicos se observan los primeros meses de vida: signos radiológicos de mineralización defectuosa en las placas de crecimiento (raquitismo) y huesos (osteomalacia) y alteraciones de la homeostasis fosfocálcica. El fenotipo clínico combina deformidades óseas, principalmente en las extremidades inferiores, y otros signos que dependen de la etiología de la resistencia.
Raquitismo tipo I dependiente de la vitamina D: Es un defecto autosómico recesivo del metabolismo de la vitamina $D$ provocado por una mutación del gen de la alfa-1-hidroxilasa (12q13.1-q13.3) que origina niveles bajos de vitamina D3. Clínicamente se caracteriza por retraso del crecimiento, hipotonía, raquitismo e hipoplasia del esmalte, con todos los dientes permanentes de coloración amarillo-marrón, cámaras pulpares cuadrangulares y grandes y raíces cortas. El examen ultraestructural muestra también anomalías de la dentina.

Síndromes autoinmunes poliglandulares: Se caracterizan por insuficiencias endocrinas múltiples. El tipo 1 se denomina también síndrome de Whitaker o distrofia ectodérmica con candidiasis mucocutánea crónica y poliendocrinopatía múltiple (diabetes tipo 1, hipoparatiroidismo, insuficiencia suprarrenal), siendo de herencia autosómica recesiva por una mutación del gen AIRE (autoimmuneregulator) localizado en el cromosoma 21q22.3. Las anomalías ectodérmicas incluyen vitíligo, alopecia y displasia del esmalte. Se desarrolla en la infancia, y la hipoplasia del esmalte de los dientes permanentes afecta al $75 \%$ de los pacientes, pudiéndose ser el primer signo clínico. Existe un defecto de la inmunidad celular que facilita la infección por cándida.

Síndrome óculo-oto-dental o globodoncia: También llamado displasia otodental, se caracteriza por un fenotipo dental conocido como globodoncia, asociado con pérdida auditiva neurosensorial para frecuencias altas y coloboma ocular. La globodoncia se presenta tanto en la dentición primaria como en la definitiva, afectando a los caninos y a los molares (por ej. dientes posteriores alargados, malformados y de aspecto bulboso, sin prácticamente poderse discernir las cúspides o los surcos). Es una enfermedad rara de prevalencia desconocida, con pocos casos de familias afectadas descritos en la literatura. El síndrome se hereda de forma autosómica dominante, a pesar de que también se han reportado casos esporádicos. En una familia británica se localizó el locus para el síndrome óculooto-dental en 20q13.1. El tratamiento odontológico es complicado, interdisciplinar y debe incluir un seguimiento regular, extracciones dentales programadas y tratamiento ortodóncico. Es necesario realizar exámenes auditivos periódicos y, en caso ne- 
cesario, utilizar audífonos, así como exploraciones oftalmológicas y, en caso de ser necesario, tratamiento ad hoc.

Síndrome óculo-facio-cardio-dental (OFCD): es un síndrome muy raro con múltiples anomalías congénitas, caracterizado por radiculomegalia dental, cataratas congénitas, dismorfia facial y cardiopatía congénita (Fig. 2).

Hasta la fecha se han registrado 20 casos en todo el mundo. La característica dental más consistente y patognomónica del OFCD es la radiculomegalia (raíces muy largas), en particular de los caninos y ocasionalmente de otros dientes, incluidos los premolares y los incisivos. La erupción dental, tanto de los dientes de leche como de la dentición permanente, es siempre lenta y retrasada. También se han registrado oligodoncia, fusiones dentarias, dientes supernumerarios, dientes permanentes deformados, defectos en el esmalte, dilaceración radicular, mala posición y mala oclusión. Las anomalías oculares observadas son cataratas congénitas bilaterales, microftalmia, déficit visual regresivo, glaucoma secundario y ptosis. Las anomalías cardíacas incluyen defecto septal ventricular, defecto del tabique auricular, cardiomegalia leve, hipertrofia ventricular y auricular, estenosis pulmonar periférica benigna y prolapso de la válvula mitral. El OFCD es un síndrome dominante ligado al cromosoma X que es letal en los varones. El gen causante de la enfermedad es el BCOR, localizado en el cromosoma Xp11.4, pero su función exacta se desconoce. El diagnóstico de OFCD es difícil para los especialistas y a menudo no se reconoce. Los datos dentales específicos (visibles en una radiografía panorámica de los maxilares) pueden ser diagnosticados fácilmente por un ortodoncista o un dentista. El tratamiento requiere un cuidado adecuado del corazón, atención oftalmológica y odontológica.

\section{Síndrome de Christ-Siemens-Touraine (displasia} ectodérmica hipohidrótica-anhidrótica): Las displasias ectodérmicas engloban un grupo heterogéneo de enfermedades caracterizadas por el desarrollo de displasias de al menos dos estructuras de origen ectodérmico. El síndrome de Christ-SiemensTouraine representa el $80 \%$ de las displasias ectodérmicas, siendo su herencia recesiva ligada al sexo, por lo que lo afecta a los varones y es heredado a través de las mujeres portadoras. Está caracterizado por tres signos que comprenden la presencia de escaso pelo (atricosis o hipotricosis), dientes ausentes o anormales (anodoncia o hipodoncia) e imposibilidad de sudar debido a la ausencia de glándulas sudoríparas (anhidrosis o hipohidrosis). La incidencia en varones se estima en 1 de cada 100.000 nacimientos, la incidencia de mujeres portadoras está alrededor de 17/100.000 mujeres. La mayoría de pacientes presentan una esperanza de vida y una inteligencia normal. Sin embargo, la pérdida de las glándulas sudoríparas, si no es reconocida, puede inducir durante la infancia temprana a hipertermia, seguida de daño cerebral o muerte. Es muy importante el diagnóstico temprano y el consejo genético. En los pacientes se considera como el problema más significativo tanto clínico como terapéutico la agenesia de los dientes y sus efectos secundarios en el crecimiento y desarrollo de la mandíbula. El trata-

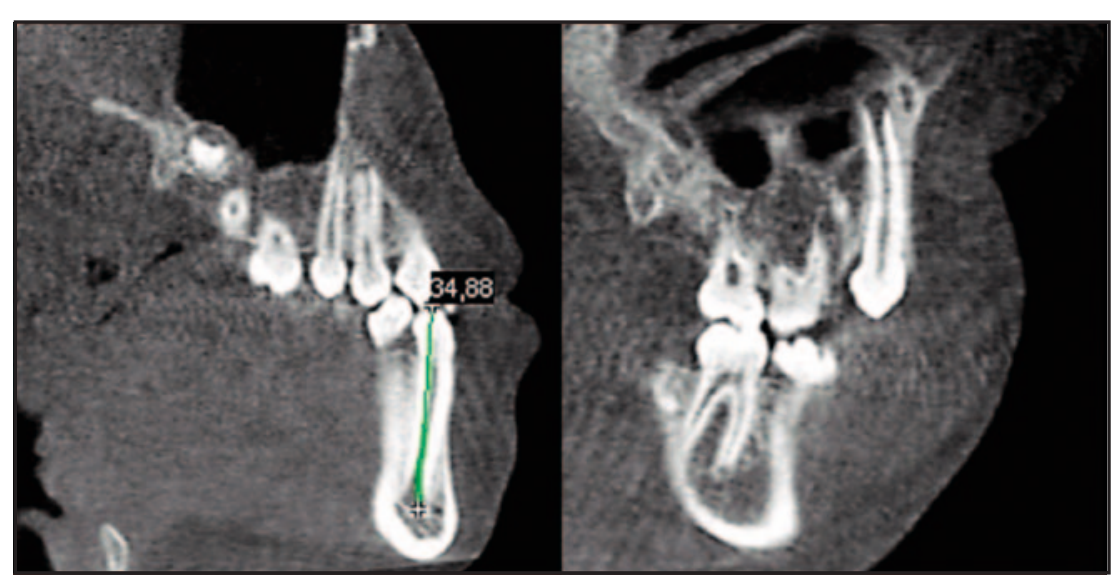

Fig. 2. Cortes tomográficos de un paciente con síndrome óculo-facio-cardio-dental en los que se aprecia gran radiculomegalia en los caninos superior e inferior. 
miento está dirigido en restablecer la función y la estética dental, y normalizar la dimensión vertical y el soporte de los tejidos blandos faciales.

Síndrome de Ellis-Van Creveld: Es una displasia condroectodérmica caracterizada por enanismo no armónico con osteocondrodisplasia y polidactilia, desarrollo psicomotor normal, y malformaciones cardíacas del tipo shunt izquierda-derecha. El pronóstico de la enfermedad depende del grado de afección cardíaca y pulmonar. El síndrome se transmite como un rasgo autosómico recesivo. Está causado por mutaciones en los genes EVC1 y EVC2 (Ellis Van Creveld) localizados en el locus 4p16. Las manifestaciones dentales incluyen dientes neonatales en el $25 \%$ de los casos, oligodoncia, principalmente en la región anterior del maxilar inferior, retraso de la erupción dentaria permanente, alteraciones de la forma dentaria, e hipoplasia del esmalte en el $50 \%$ de los casos.

Síndrome de Hallermann-Streiff-François o síndrome óculo-mandíbulo-facial: Se caracteriza mandíbula hipoplásica, nariz aguileña, baja estatura proporcionada (2/3), hipotricosis, microftalmia, cataratas congénitas, hipotricosis, atrofia de la piel de la cara e hipoplasia de las clavículas y las costillas. Cerca de un $15 \%$ de los casos presentan un déficit intelectual. A nivel dental, puede haber dentición neonatal y en el $80 \%$ de los pacientes hay hipodoncia. Se desconoce aún la base genética.

\section{ALTERACIONES GENÉTICAS DE LA DENTINOGENESIS}

El odontoblasto es la célula secretora de la matriz dentinaria. Las proteínas de la matriz extracelular del hueso y de la dentina son muy similares, estando ambas constituidas principalmente por colágeno tipo I, proteína acídicas y proteoglicanos. El colágeno forma el entramado para la deposición del calcio y el fosfato y la formación de cristales de hidroxiapatita. Las proteínas no colágenas, proteína de la matriz dentinaria 1 (DMP1), la sialoproteína dentinaria (DSP) y la fosfoproteína dentinaria (DPP), aunque en porcentaje muy inferior, tienen una gran importancia funcional en el proceso de mineralización, controlando la iniciación y el crecimiento de los cristales de hidroxiapatita y regulando la dentinogénesis.
Shields (16) (1973) clasificó los trastornos genéticohereditarios de la dentina en dos grupos: la dentinogénesis imperfecta (DI), con los tipos I, II, y III, y la displasia dentinaria (DD), con los tipos I y II. La DI-I es la manifestación dental de la osteogénesis imperfecta, una enfermedad ósea de herencia autosómica dominante. La DI-II, la DI-III, la DD-I y la DD-II se presentan de forma aislada, no sindrómica, con diferentes fenotipos dentales, siendo su herencia mas frecuente la autosómica dominante.

\section{Alteraciones genéticas no sindrómicas de la dentinogénesis}

Comprenden un grupo de enfermedades de herencia autosómica dominante caracterizadas por una estructura anormal de la dentina que afecta bien sólo a los dientes primarios o a ambas denticiones. Las tres entidades DI-II, DI-III y DD-II han sido mapeadas en el cromosoma 4q21, siendo su factor causal una mutación en el gen que codifica la sialofosfoproteína dentinaria (DSPP). El gen de la DSPP es bicistrónico. Su transcrito origina las dos proteínas principales de la matriz dentinaria, la sialoproteína dentinaria (DSP) y la fosfoproteína dentinaria (DPP). Puede concluirse que, por lo que a estas tres entidades se refiere, la clasificación propuesta por Shields refleja de hecho, más que enfermedades diferentes, una expresión variable de una misma patología. Por el contrario, en la etiología de la DD-I no está implicado el gen DSSP.

Dentinogénesis imperfecta tipo II (DI-II): La característica clínica típica de la DI-II es la presencia de dientes translucidos-opalescentes de color azul-marrón claro en ausencia de anomalías óseas (Fig. 3). Tiene una incidencia de entre $1 / 6.000$ a 1/8.000 personas. La afectación de los dientes primarios suele ser mas grave que la de los permanentes. Aunque el esmalte no está afectado, tiende a fracturarse por existir una unión amelodentinaria anómala y estar soportado por una dentina muy blanda, dando a los dientes un aspecto de pseudo-AI, si bien el aspecto opalescente de la dentina expuesta facilita el diagnóstico.

La rápida atrición de la dentina provoca el acortamiento de las coronas dentarias, que pueden llegar a quedar a nivel gingival (dientes sin corona). El aspecto radiográfico es patognomónico: la dentina es 


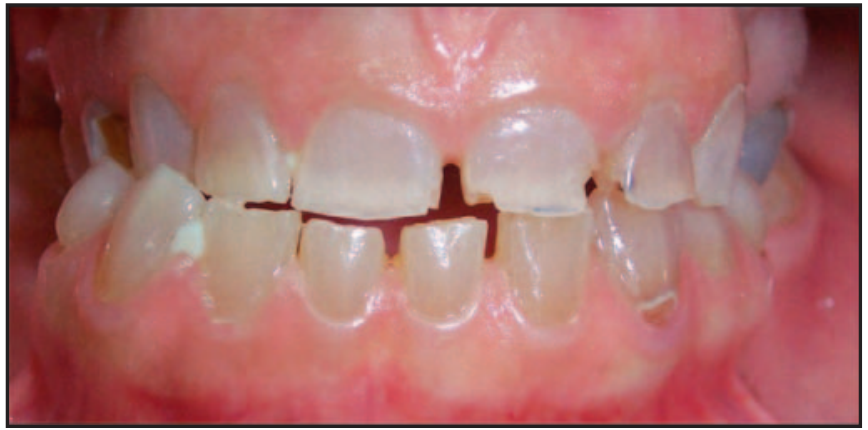

Fig. 3. Dentinogénesis imperfecta tipo II.

muy radiolúcida, las coronas tienen un aspecto globuloso, con una marcada constricción cervical; las raíces son cortas y romas con conductos radiculares muy estrechos; las cámaras pulpares son inicialmente más amplias que las normales, pero se van obliterando progresivamente por la formación de dentina anómala y la formación de pulpolitos, volviéndose pequeñas y opacas (dentinificadas). Las infecciones periapicales plantean con frecuencia problemas, provocando abscesos recurrentes. La predisposición a la infección bacteriana se debe, posiblemente, a la invasión bacteriana a través de los túbulos dentinarios expuestos al medio oral o a necrosis pulpares consecutivas a la obliteración de la cámara pulpar. Se ha sugerido que las proteínas de la matriz dentinaria podrían tener un papel activo en el reclutamiento de las células inflamatorias. El diagnostico diferencial debe hacerse con las formas hipocalcificadas de AI, la porfiria eritropoyética congenital, síndromes en los que hay pérdida prematura de la dentición (síndrome de Chediak-Hegashi, histiocitosis X, síndrome de Papillon-Lefevre), descoloraciones por tetraciclinas y los raquitismos dependientes o resistentes a la vitamina D. El tratamiento incluye la eliminación de todos los focos infecciosos y dolorosos orales, la protección de los dientes frente a la atrición mediante coronas de recubrimiento total, la utilización de técnicas avanzadas de odontología estética, sobredentaduras, implantes dentales, etc. Si el tratamiento comienza en la infancia, tras la erupción dentaria, pueden conseguirse una estética y función aceptables.

Dentinogénesis imperfecta tipo III (DI-III): Esta entidad se ha descrito en la subpoblación trirracial de Brandywine (Maryland, USA). Los dientes presentan una decoloración de color ámbar, grave atrición, exposiciones pulpares múltiples, y un aspecto radiográfico característico de dientes en cáscara. La dentición permanente tiene el esmalte picoteado y es frecuente la mordida abierta. Los dientes primarios tienen grandes cámaras pulpares. Todos los dientes están hipocalcificados.

Displasia dentinaria tipo I (DD-I): Denominada también forma radicular de displasia dentinaria. No se relaciona con el gen DSPP, permaneciendo desconocida su base molecular. Aparece en 1/100.000 personas. A diferencia de la DI, los dientes no pierden el esmalte y las coronas tienen un aspecto clínico normal, aunque pueden ser ligeramente opalescentes. Afecta a todos los dientes de ambas denticiones. Lo más llamativo es la presencia de raíces muy cortas, cónicas, que no soportan adecuadamente al diente, por lo que hay pérdida prematura de piezas dentarias. El diagnóstico es radiográfico: raíces cortas, cónicas, a veces ausentes, con ápices redondeados (rootlessteeth), cámaras pulpares y conductos radiculares casi completamente obliterados y frecuentes lesiones periapicales. Los molares suelen ser taurodónticos por fusión de las raíces.

Displasia dentinaria tipo II (DD-II): También denominada forma coronaria de la DD. Es menos frecuente que la DI. La dentición temporal muestra un aspecto clínico similar al de la DI, mientras que su aspecto radiográfico es parecido al observado en la DD-I. Los dientes permanentes tienen un color y forma radicular normales. Radiográficamente, las cámaras pulpares tienen una forma de llama, con frecuentes pulpolitos; las raíces tienen una forma normal, pero los conductos radiculares aparecen obliterados. No suele haber lesiones periapicales.

\section{Síndromes hereditarios asociados a dentinogénesis imperfecta y a displasias de la dentina}

La dentinogénesis imperfecta se asocia a un gran número de síndromes hereditario, sólo se tratarán aquellos cuya base genética es conocida y los que tienen características más significativas. Algunos de ellos están producidos por mutaciones que afectan a la síntesis del colágeno (osteogénesis imperfecta, 
síndrome de Ehlers-Danlos y síndrome de Goldblatt), mientras que otras no.

\section{Dentinogénesis imperfecta asociada a osteogé-} nesis imperfecta (DI-I): Es la manifestación dental observada en los pacientes con osteogénesis imperfecta (OI), una enfermedad de los huesos de herencia autosómica dominante. Sus manifestaciones son idénticas a las de la DI-II, pero en estos pacientes se observa, además, una desmineralización generalizada de los huesos que los hace muy susceptibles a las fracturas. La OI se produce por la mutación de los genes COL1A1 (17q21) y COL1A2 (7q21.1), que codifican las cadenas de colágeno tipo I, el $90 \%$ del colágeno que forma la matriz dentinaria. La DI-I es especialmente frecuente en los tipos IIIByIVB de la OI, mientras que es rara en la del tipo I. Las alteraciones dentarias, clínicas o radiográficas, son muy útiles para el diagnóstico precoz de la OI. Debe hacerse un estudio radiográfico dental a todos los pacientes en los que se sospeche OI. Los dientes tienen una coloración grisácea-marrón, con fracturas de esmalte y atrición, estando, en general, la dentición primaria más afectada que la permanente. A nivel radiográfico, son característicos la marcada constricción cervical, la progresiva obliteración del espacio pulpar y la presencia de raíces delgadas y cortas. En OI tipo I se ha descrito una cámara pulpar oval con extensiones apicales en la porción coronal de las raíces, de forma similar a lo observado en la DD-II. En muchos pacientes se observan radiolucideces apicales en todos los incisivos permanentes inferiores. En la OI tipo III y IV son frecuentes los dentículos. En la OI pueden encontrarse también coronas dentarias traslúcidas o con bandas transversales de decoloración, erupción ectópica, impactación de molares permanentes, agenesias dentarias, y anomalías de la oclusión, como mordida abierta anterior o posterior y mordida cruzada.

Síndrome de Ehlers-Danlos (SED): Se caracteriza por hiperlaxitud ligamentaria. Aunque la mayoría de los pacientes con SED no presentan alteraciones de la dentina, la duplicación parcial del gen COL1A2 puede ocasionar dientes opalescentes, y la mutación del gen ADAMTS2 se asocia a la presencia de agenesias múltiples, dientes supernumerarios, anomalías de la dentina, calcificaciones pulpares y raíces displásicas (cortas, dilaceradas).
Síndrome de Goldblatt: En esta rara enfermedad aparece displasia epondilometafisaria, laxitud articular y DI o DD-II. Los dientes primarios son opalescentes mientras que los permanentes son normales. Parece deberse a una disminución en la síntesis de colágeno tipo I por la sustitución de una base en el gen COL2A1.

Displasia inmuno-ósea de Schimke: Es una enfermedad autosómica recesiva caracterizada por displasia espondiloepifisaria, disfunción renal e inmunodeficiencia de células T. Se produce por una mutación del gen SMARCAL1. Las alteraciones dentarias son similares a la DI.

Calcinosis tumoral hiperfosfatémica familiar: Es una enfermedad autosómica recesiva en la que se asocian calcificaciones cutáneas y subcutáneas con niveles altos de fosfatemia. Cuando se produce por mutación del gen GALNT3, hay displasia dentinaria con raíces cortas y bulbosas, pulpolitos y obliteración parcial de la cavidad pulpar.

Raquitismo hipofosfatémico familiar resistente a la vitamina $D$ o síndrome de Albright: Por su tipo de herencia se denomina también hipofosfatemia dominante ligada al sexo. La enfermedad está causada por una mutación en el gen que codifica la endopeptidasa reguladora del fosfato localizado en el locus Xp22.2-p22.1, que se expresa en los osteoblastos, osteocitos, odontoblastos y en la glándula paratiroides, con alteración de la osteogénesis y la odontogénesis. Es la forma de raquitismo mas prevalente en los países desarrollados, con una prevalencia en torno a 1/20.000 personas. El paciente tiene retraso del crecimiento, displasia ósea, hipofosfatemia, existiendo una alteración de la reabsorción renal de fosfato y vitamina D. A nivel dental, hay alteraciones tanto histológicas como radiográficas en ambas denticiones. Son características las fisuras o cracks en la dentina que se extienden desde la unión amelodentinaria hasta la pulpa. En el esmalte también pueden observarse zonas hipocalcificadas. A través de estos defectos estructurales, las bacterias pueden invadir la pulpa, siendo frecuentes los abscesos múltiples de origen dentario a nivel de los incisivos inferiores, en pacientes con dientes libres de caries y sin traumatismos ni enfermedad periodontal. En la radiografía se observan 
cámaras pulpares agrandadas, raíces cortas, lámina dura poco definida y densidad similar de esmalte y dentina. El retraso en la erupción dentaria es frecuente.

Síndrome de Seckel: Se caracteriza por baja estatura, microcefalia, retraso mental y perfil facial de pájaro. Ha sido mapeado en el cromosoma 8p11q11. Las anomalías dentarias incluyen anodoncia o hipodoncia, hipoplasias de esmalte y dentina, raíces cortas y taurodontismo. En contraste con el desarrollo óseo, la maduración dental es acorde a la edad cronológica.

\section{ANOMALÍAS DENTARIAS DE ORIGEN GENÉTICO-HEREDITARIO}

El número de dientes que conforman la dentición humana se fijó hace millones de años. De hecho, uno de los rasgos que permiten identificar a una especie de primate como homínido es tener 32 dientes distribuidos en 8 incisivos, 4 caninos, 8 premolares y 12 molares. Las alteraciones en el número de dientes pueden presentarse aisladas o en el marco de un síndrome hereditario.

\section{Agenesias dentarias no sindrómicas}

La agenesia o ausencia congénita de un diente se diagnóstica cuando no ha erupcionado en la cavidad oral y no es visible en la radiografía. Excluyendo el tercer molar, se definen la hipodoncia como la agenesia de uno a seis dientes, la oligodoncia como la falta de mas de seis dientes y la anodoncia como la ausencia completa de dientes. En el momento del nacimiento pueden verse en la radiografía todos los dientes primarios y la cripta ósea de los primeros molares. El examen clínico-radiográfico a los 3-4 años y a los 12-14, permiten diagnosticar la agenesia de dientes primarios y permanentes, respectivamente.

La oligodoncia se asocia a numerosos síndromes, especialmente a las displasias ectodérmicas. En estos casos, los dientes remanentes presentan anomalías de la forma y tamaño, siendo con frecuencia microdónticos y/o conoides. Por el contrario, en los casos de alteraciones del número dentario no sindrómicas, la forma del diente es generalmente normal. A la agenesia dentaria pueden asociarse otras anomalías (17), como retraso en la erupción dentaria, erupción ectópica, transposición (18), microdoncia, anomalías de la forma y taurodontismo (Fig. 4).

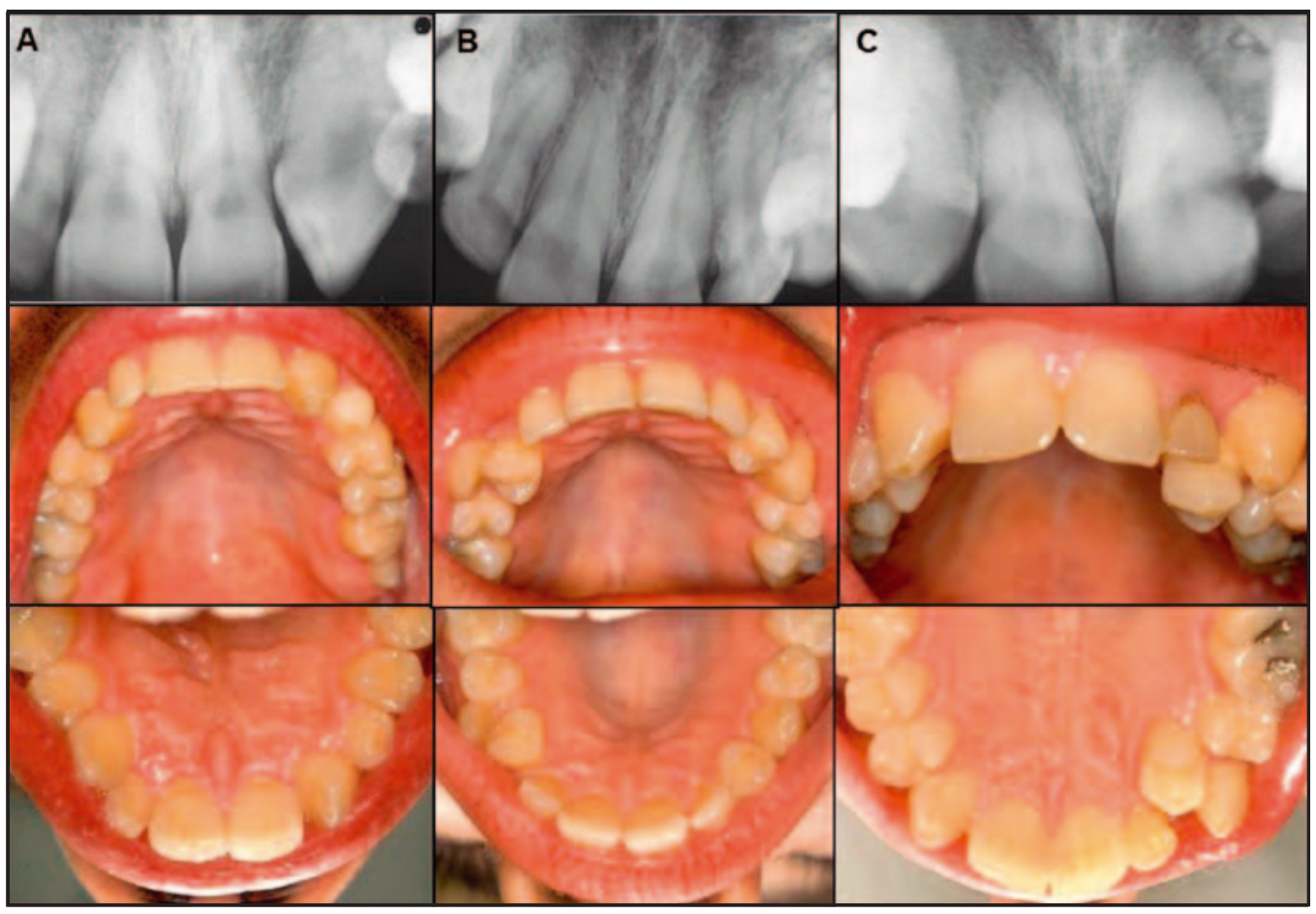

Fig. 4. Anomalías del incisivo lateral superior en tres hermanos. A) Transposición completa de canino $\mathrm{x}$ incisivo lateral en el lado izqdo. del maxilar superior. Ambos incisivos laterales son conoides. B) Transposición bilateral de canino $\mathrm{x}$ primer premolar, completa en el lado izqdo. del maxilar superior e incompleta en el lado dcho. C) Agenesia bilateral de incisivos laterales superiores, persistencia del incisivo lateral primario izqdo. y transposición del canino $\mathrm{x}$ primer premolar en el lado izqdo. 
Hay una fuerte correlación entre la hipodoncia en las denticiones primaria y permanente. Los niños con hipodoncia en la dentición primaria normalmente muestran también hipodoncia en los permanentes correspondientes. La prevalencia de oligodoncia en la dentición primaria varía entre el 0,4\% y el $0,9 \%$ en la población europea. Las agenesias de dientes permanentes en Europa tienen una prevalencia del $4,6 \%$ en hombres y del 6,3\% en mujeres. El diente mas afectado es el tercer molar (23-28\% de todas las agenesias), seguido por el segundo premolar mandibular, y el incisivo lateral y el segundo premolar maxilares. La agenesia dental unilateral es más frecuente que la bilateral, aunque en el caso del incisivo lateral superior es más frecuente la bilateral.

La anodoncia o ausencia congénita de todos los dientes no sindrómica es extremadamente rara, habiéndose sugerido que podría deberse a un estado homocigótico del gen responsable de la agenesia y el conoidismo de los incisivos superiores. Estudios realizados en familias han demostrado que la hipodoncia y la oligodoncia, no sindrómicas, pueden heredarse como un rasgo autosómico dominante de penetrancia incompleta y expresividad variable. Los incisivos laterales conoides se asocian a agenesia de segundos premolares. La frecuencia y el patrón de herencia de la agenesia, conoidismo y microdoncia del incisivo lateral superior observado en diferentes familias sugiere que las tres anomalías son diferentes grados de expresión de un gen autosómico dominante de penetrancia reducida (Figs. 4 y 5).

Se han identificado tres anomalías genéticas responsables de oligodoncia:

1. La oligodoncia por mutaciones del gen homeobox MSX1 (4p16.1) se manifiesta con mayor frecuencia por agenesia de segundos premolares y de terceros molares. Puede asociarse a hendidura labio-palatina.

2. La oligodoncia por mutaciones del gen PAX 9 (14q12-q13) produce agenesia de la mayoría de los molares permanentes con / sin hipodoncia en la primera dentición.

Algunos pacientes presentan también agenesias de premolares o de incisivos centrales mandibulares.

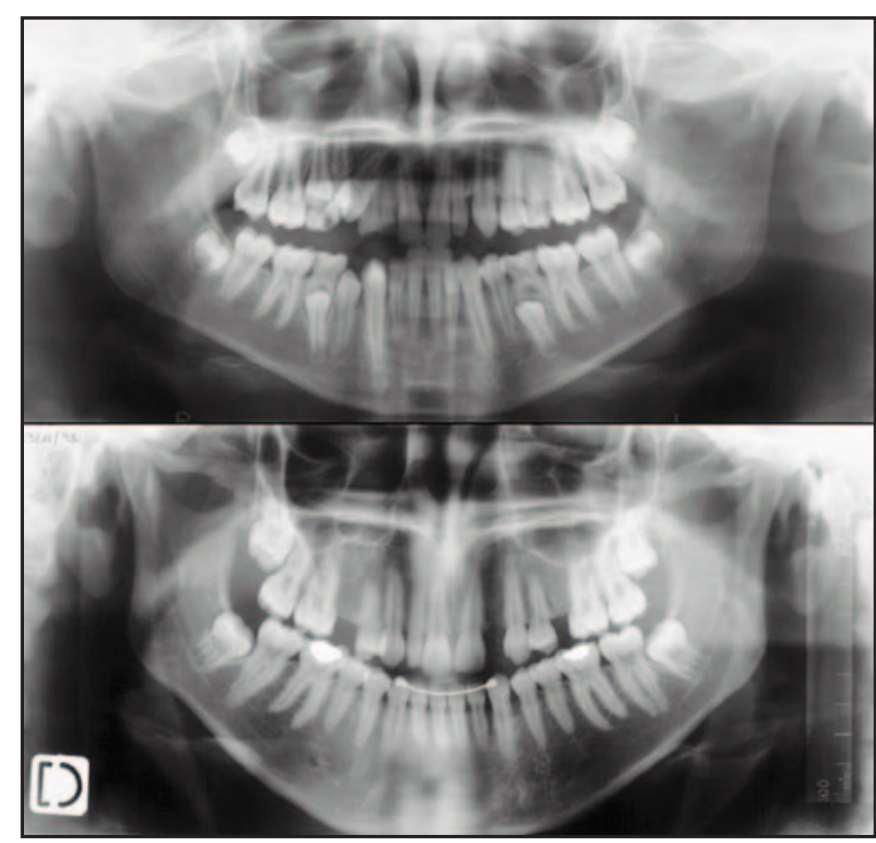

Fig. 5. Agenesia bilateral de incisivos laterales superiores en dos hermanos.

3. La oligodoncia por mutaciones del gen AXIN2 (17q23-24) se caracteriza por agenesias dentarias múltiples de dientes permanentes y cáncer colorrectal de penetrancia muy alta.

\section{Síndromes hereditarios asociados a agenesia dentaria}

Son varios los síndromes genético-hereditarios en los que se encuentran agenesias dentarias.

Síndrome de Down: La agenesia dentaria se da en el $70 \%$ de las mujeres y el $91 \%$ de los varones con síndrome de Down. El incisivo lateral superior, el central inferior, y los segundos premolares son los más frecuentemente afectados. La agenesia uni o bilateral de los incisivos laterales superiores se encuentra en mas del $10 \%$ de los pacientes, siendo muy frecuente también el conoidismo de los laterales superiores.

Síndrome de Wolf-Hirschhorn: Se produce por la delección de la región subterminal del cromosoma 4 p. Se asocia a erupción retrasada, fusión de incisivos y oligodoncia. 
Síndrome de Kallmann: Es una enfermedad del desarrollo en la que se asocian hipogonadismo hipogonadotrópico y anosmia. La prevalencia es de 1/ 10.000 en hombres y 1/50.000 en mujeres. Las anomalías dentarias consisten en agenesias de incisivos maxilares y premolares. Se ha descrito la ausencia congénita de los cuatro primeros molares permanentes y los caninos mandibulares.

Displasias ectodérmicas: Ya se ha hablado de este grupo de enfermedades anteriormente. De los aproximadamente 170 tipos clínicos, la mutación causante sólo se ha identificado en menos de 30.

En la displasia ectodérmica hipohidrótica ligada al sexo la oligodoncia es casi constante y, en algún caso, se ha observado anodoncia. Los incisivos superiores, los cuatro primeros molares y los segundos molares inferiores son microdónticos y con anomalías de la forma. Las mujeres portadoras pueden identificarse mediante el examen dental: presentan incisivos y caninos microdónticos y conoides, algunas agenesias dentarias y taurodontismo de los segundos molares primarios.

La displasia ectodérmica hipohidrótica con incontinencia de pigmentos y déficit inmune, de herencia dominante ligada al sexo, es letal en los hombres, y en las mujeres se manifiesta por alteraciones en la piel, los ojos, el sistema nervioso y los dientes. Las alteraciones dentales aparecen en el $70 \%$ de los pacientes, afectando a ambas denticiones. Se observan hipodoncia, conoidismo y erupción retrasada.

Síndrome lácrimo-aurículo-dento-digital: Es una enfermedad de herencia autosómica dominante en la que hay aplasia, atresia o hipoplasia de los sistemas lacrimal y salival, orejas puntiagudas, sordera, y anomalías en los dedos y en los dientes. A nivel dental se pueden apreciar agenesias de incisivos laterales maxilares, incisivos laterales microdónticos y conoides, y displasia del esmalte.

Síndrome de Rieger: Se diagnostica cuando la malformación de Axenfeld-Rieger, una anomalía de la cámara anterior del ojo que se da en 1/200.000 personas y en la que desarrollan glaucoma el $50 \%$ de los afectados, se asocia con malformaciones cra- neofaciales, somáticas y dentales. Es característico el exceso de piel periumbilical. Las anomalías dentarias son la clave para el diagnóstico, consistiendo en agenesias dentarias en ambas denticiones, especialmente de los incisivos superiores y caninos. Hay también hipoplasia del esmalte, conoidismo, raíces cortas, taurodontismo y retraso de la erupción.

Síndrome de Johansson-Blizzard: De herencia autosómica recesiva, se caracteriza por insuficiencia pancreática exocrina con malabsorción, hipoplasia de las alas de la nariz, hipotiroidismo, sordera, hipotiroidismo, retraso del crecimiento, retraso mental y agenesias dentarias de dientes permanentes. Se produce por una mutación del gen mapeado en 15q14-q21.1.

\section{Hipergenesias dentarias no sindrómicas}

La prevalencia de dientes supernumerarios es del $0,2-0,9 \%$. Pueden aparecer en cualquier zona de la arcada dentaria, aunque son más frecuentes en el maxilar superior, especialmente las hipergenesias dentarias aisladas. La presencia de dientes supernumerarios tiene un factor genético bien probado. Existen numerosos casos publicados de mesiodens (Fig. 6) con incidencia familiar y se han observado en gemelos monocigóticos). Sin embargo, por ahora no se ha identificado ninguna mutación responsable de hipergenesia dentaria.

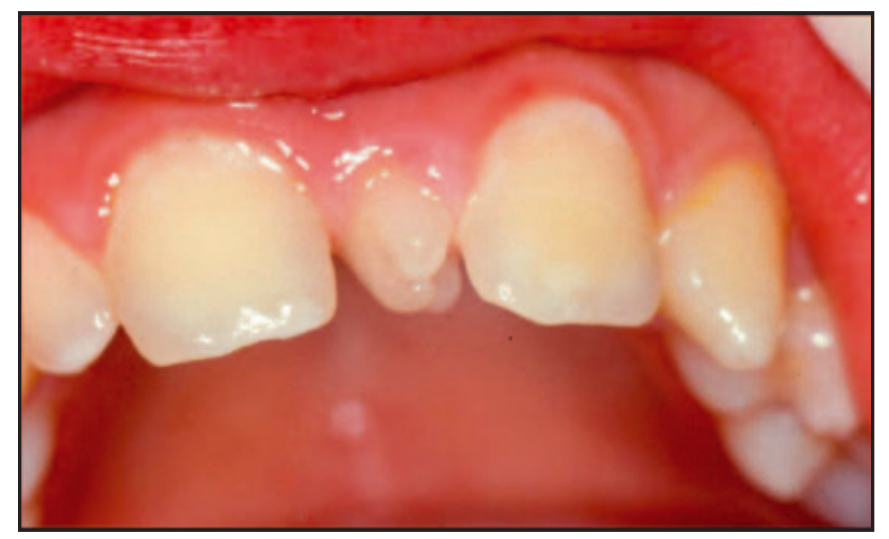

Fig. 6. Mesiodens: diente supernumerario en la región interincisiva superior. El paciente presentaba también agenesia del incisivo lateral superior izquierdo. 


\section{Síndromes hereditarios asociados a hipergenesia dentaria}

La presencia de dientes supernumerarios puede ser un rasgo aislado, pero son muchos los síndromes hereditarios de base genética bien conocida en los que una de sus características es la presencia de un número de dientes superior al normal.

Displasia cleido-craneal: Es una enfermedad autosómica dominante que afecta a los huesos y a los dientes. Está causada por una mutación del gen RUNX2, que codifica un factor de transcripción específico de los osteoblastos mapeado en el locus 6p21. Hay hipoplasia de los huesos del cráneo y las clavículas. Las anomalías dentarias que aparecen son dientes supernumerarios (a veces una tercera dentición), retraso en la erupción, permanencia de dientes temporales y maloclusión.

Poliposis adenomatosa del colon o síndrome de Gardner: Es una enfermedad autosómica dominante en la que se asocian la presencia de pólipos intestinales, osteomas múltiples y tumores de piel y tejidos blandos. Se altera el locus 5q21-q22. Los pólipos se malignizan en el $100 \%$ de los casos, por lo que es muy importante el diagnóstico precoz de la enfermedad. Las alteraciones dentales son dientes impactados, dientes supernumerarios, agenesias dentarias y raíces largas y puntiagudas en los dientes posteriores. Los osteomas radiopacos ocultos a nivel de la mandíbula son un signo precoz de la enfermedad que precede a la poliposis colónica. Se ha propuesto un índice dental, el DPRS (19), para su diagnóstico precoz, basado en los hallazgos radiográficos de la ortopantomografía.

Síndrome de Nance-Horan: Es una alteración de herencia ligada al sexo caracterizada por cataratas congénitas, dismorfismo, anomalías de la forma dentaria (dientes en destornillador), incisivos supernumerarios y retraso mental.

\section{BIBLIOGRAFÍA}

1. Jiménez-Rubio A, Segura-Egea JJ, Feito JJ. A case of combined dental development abnormalities: importance of a thorough examination. Endod Dent Traumatol 1998;14:99-102.
2. Segura-Egea JJ, Jiménez-Rubio A. Anomalías dentarias del número y de la posición: a propósito de un caso clínico compejo. Rev EurOdontoEstomatol 1999; 5:285-90.

3. Hattab FN, Segura-Egea JJ.Simultaneous presence of a primary second molar and second premolar in the same jaw of adult male: report of case. Dental News 2003;10:9-11.

4. Jiménez-Rubio A, Segura-Egea JJ, Jiménez-Planas A, Llamas R. Multiple dens invaginatus affecting maxillary lateral incisors and a supernumerary tooth. Endod Dent Traumatol 1997;13:196-8.

5. Segura-Egea JJ, Jiménez-Rubio A, Monje F. Fusión bilateral de los incisivos permanentes mandibulares. Presentación de dos casos clínicos. RevEurOdonto-Estomatol 2000; XII:339-44.

6. Segura-Egea JJ, Jiménez-Rubio A, Esteban I. Diagnóstico radiográfico «in vivo» de un segundo premolar mandibular con tres conductos y taurodontismo. Endodoncia 2000;18:140-3.

7. Jiménez Pinzón A, Segura Egea JJ. Taurodontismo en premolares inferiores: presentación de dos casos y revisión de la literatura. Archiv. Odontoestomatol 2003;19:280-4.

8. Bailleul-Forestier I, Berdal A, Vinckier F, de Ravel T, Fryns JP, Verloes A. The genetic basis of inherited anomalies of the teeth. Part 2: Syndromes with significant dental involvement. Eur J Med Gen 2008;51:273-91.

9. Jiménez-Rubio A, Segura-Egea JJ. Los genes "homeobox" y la morfodiferenciación dentaria: a propósito de un caso de anomalías dentarias asociadas. RevEurOdonto-Estomatol 1999;XI: 111-6.

10. Portal Orphanet: http://www.orpha.net/consor4.01/ www/cgi-bin/index.php?lng=ES.

11. Backman B, Holmgren G. Amelogenesis imperfecta: a genetic study, Hum Hered 1988;38:189206. 
12. Witkop CJ. Amelogenesis imperfecta, dentinogénesis imperfecta and dentin dysplasia revisited: problems in classification. J Oral Pathol 1988;17: 547-53.

13. Nusier M, Yassin O, Hart TC, Samimi A, Wright JT. Phenotypic diversity and revision of the nomenclature for autosomal recessive amelogénesis imperfecta, Oral Surg Oral Med Oral Pathol Oral RadiolEndod 2004;97:220-30.

14. Ozdemir D, Hart PS, Firatli E, Aren G, Ryu OH, Hart TC. Phenotype of ENAM mutations is dosagedependent. J Dent Res 2005;84:1036-41.

15. Bailleul-Forestier I, Molla M, Verloes A, Berdal A. The genetic basis of inherited anomalies of the teeth: Part 1: Clinical and molecular aspects of non-syndromic dental disorders. Eu J Med Gen 2008;51:273-91.

16. Shields ED, Bixler D, el-Kafrawy AM. A proposed classification for heritable human dentine defects with a description of a new entity. Arch Oral Biol 1973;18:543-53.
17. Segura-Egea JJ, Jiménez-Rubio A. Concomitant hypohyperdontia: simultaneous occurrence of a mesiodens and agenesis of a maxillary lateral incisor. Oral Surg Oral Med Oral Pathol Oral RadiolEndod 1998;86:473-5.

18. Segura-Egea JJ, Hattab F, Ríos V. Maxillary canine transpositions in two brothers and one sister: associated dental anomalies and genetic basis. ASDC.JDent Child2002;69:54-8.

19. Aggarwal VR, Sloan P, Horner K, Macfarlane TV, Clancy T, Evans G, Thakker N. Dento-osseous changes as diagnostic markers in familial adenomatous polyposis families. Oral Dis 2003; 9:29-33.

\section{CORRESPONDENCIA}

Dr. Juan J. Segura-Egea

Dpto. de Estomatología. Universidad de Sevilla

Avicena, s/n

41009, Sevilla. España

E-mail: segurajj@us.es 